\title{
Intervensi Bagi Guru SD Perempuan di Masa Pandemi COVID-19: Sebuah Pelatihan Peningkatan Kebahagiaan Psikologis
}

\section{The Intervention for Elementary School Female Teacher in COVID-19 Pandemic: The Training of Psychological Well-being Enhancement}

\author{
Umi Fitriati Nasihah(1)* \& Ratna Djuwita(2) \\ Fakultas Psikologi, Universitas Indonesia, Indonesia \\ Disubmit: 22 Januari 2021; Diproses: 29 Januari 2021; Diaccept: 16 Maret 2021; Dipublish: 05 April 2021 \\ *Corresponding author: E-mail: umi.fitriati@gmail.com
}

\begin{abstract}
Abstrak
Pelaksanaan PJJ membawa tantangan bagi guru-guru di Indonesia, termasuk guru SD perempuan. Kebahagiaan psikologis menjadi hal penting untuk dicapai agar guru mampu menjalankan peran dengan optimal. Penelitian intervensi dalam bentuk pelatihan ini bertujuan untuk meningkatkan kebahagiaan psikologis guru dalam masa pandemi COVID-19. Desain penelitian pada pelatihan ini adalah one group pretest-posttest design. Partisipan dalam penelitian ini berjumlah 16 orang. Materi pelatihan yang diberikan dalam pelatihan ini adalah mindfulness dan komunikasi. Pengukuran dilakukan terhadap ketiga variabel sebelum dan sesudah pelatihan dilakukan. Meskipun dari perhitungan secara keseluruhan tidak ditemukan kenaikan signifikan, namun jika dilihat perindividu maka terdapat 9 orang mengalami kenaikan nilai pretest ke posttest pada kebahagiaan psikologis, 12 orang mengalami kenaikan pada pengukuran mindfulness dan 9 orang mengalami kenaikan pada pengukuran komunikasi. Kesimpulan dari penelitian ini berdasarkan analisis statistik tidak terjadi peningkatan yang signifikan pada pengetahuan partisipan terhadap kebahagiaan psikologis, tapi secara kualitatif partisipan pelatihan merasakan pelatihan memiliki manfaat bagi mereka dan berpotensi positif meningkatkan kebahagiaan psikologis.
\end{abstract}

Kata Kunci: COVID-19; Kebahagiaan psikologis; Komunikasi; Mindfulness; Pelatihan guru

\begin{abstract}
The implementation of PJJ creates some challenges for teachers in Indonesia, especially for elementary school female teachers. Psychological well-being is an important thing to achieve so that teachers can carry out their roles optimally. The intervention study in the form of training aimed to improve the psychological well-being of teachers during the COVID-19 pandemic. The research design in this training was one group pretest-posttest design with 16 participants. The raining materials provided in this form of training were mindfulness and communication. Measurements were made on the three variables before and after the training held. Although from the overall calculation there was no significant increase, but if the training was viewed individually, 9 people experienced an increase in the pretest to posttest psychological well-being, 12 people experienced an increase in mindfulness and 9 people experienced an increase in communication measurement. Even though there was an increase in the value, it was not significant. The conclusion of this study based on statistical analysis that there was no significant improvement in participants' knowledge of psychological well-being, but qualitatively the training participants felt that the training gave benefits for them and had the potential to positively increase psychological well-being.
\end{abstract}

Keywords: COVID-19; Communication; Mindfulness; Psychological well-being; Teacher training

DOI: https://doi.orq/10.51849/i-p3k.v2i1.87

Rekomendasi mensitasi :

Nasihah, U.,F \& Djuwita, R. 2021. Intervensi Bagi Guru SD Perempuan di Masa Pendemi COVID-19: Sebuah Pelatihan Peningkatan Kebahagiaan Psikologis. Jurnal Penelitian Pendidikan, Psikologi dan Kesehatan (J-P3K), 2 (1): 39-51. 


\section{PENDAHULUAN}

Pandemi COVID-19 yang sedang kita hadapi memberikan pengaruh pada berbagai ranah dalam kehidupan kita, salah satunya pada bidang pendidikan. Pendidikan yang biasanya dilakukan dengan tatap muka di sekolah-sekolah harus dihentikan selama pandemi COVID19 karena alasan kesehatan dan keselamatan guru dan siswanya. Sekolahsekolah menerapkan Pembelajaran Jarak Jauh (PJJ) dimana segala bentuk kegiatan belajar mengajar dilakukan melalui daring.

Pembelajaran dengan metode daring belum sepenuhnya bisa dengan mudah dilakukan oleh seluruh siswa dan guru di Indonesia. Apalagi pada anak kelas 1-3 SD yang masih memerlukan pendampingan orangtua saat PJJ (Purwanto et al., 2020). Keberhasilan pembelajaran mereka dipengaruhi oleh kondisi lingkungannya.

Selain itu, terkait dengan guru perempuan dan peran yang dilaksanakan selama PJJ ini juga memiliki dampak tersendiri pada keberhasilan pembelajaran. Guru perempuan sendiri dibandingkan dengan guru laki-laki memiliki perbedaan terkait peran yang dilaksanakan, guru perempuan tidak hanya berperan memberi pelajaran di sekolah tetapi juga melakukan pekerjaan rumah tangga serta mengurus keluarganya (Nurmayanti et al., 2014). Hal ini juga berdampak pada batasan yang dimiliki oleh guru terhadap kehidupan yang dimilikinya dengan kehidupan pekerjaannya (Hunter et al., 2019).

Selama PJJ dilaksanakan, bagi guru seolah tidak ada jam kerja yang berlaku, saat malam hari pun terkadang guru masih mengurusi pekerjaannya seperti mengoreksi ataupun menanggapi orangtua murid yang menyetorkan tugas anaknya (Dewi, 2020). Kondisi penuh tekanan dan beban kerja dapat memberikan dampak buruk pada kondisi kebahagiaan psikologis individu (Braun et al., 2019). Kebahagiaan psikologis sendiri memiliki peran penting agar seseorang mampu melaksanakan kegiatan seharihari dengan optimal (Huppert, 2009).

Guru perempuan yang mengajar pada jenjang SD dan memiliki anak kelas 1-3 SD agar optimal menjalankan peran perlu meningkatkan kebahagiaan psikologis. Beberapa intervensi untuk meningkatkan kebahagiaan psikologis diketahui dari penelitian meta analisis yang dilakukan Weiss et al., (2016) dengan strategi menggunakan mindfulness dan ketrampilan komunikasi. Misalnya intervensi ACT dan mindfulnesss group intervention (Fledderus et al., 2010); Mindfulness-based group intervention (Josefsson et al., 2014) dan Web-based cognitive training (Borness et al., 2013).

Hasil penelusuran literatur ini yang kemudian menjadi pertimbangan untuk menyusun intervensi dalam bentuk pelatihan. Dalam masa pandemi COVID19, peneliti tidak mungkin melaksanakan pelatihan secara tatap muka. Berdasarkan diskusi dengan Tim Pengmas UI dan mengamati fenomena di lapangan diputuskan untuk mengembangkan sebuah intervensi dalam bentuk pelatihan daring. Pelatihan dilakukan secara daring dan menggunakan sebuah aplikasi berjudul PENGMAS untuk membantu para partisipan berlatih.

Pelatihan yang dilaksanakan berlandaskan teori experiental learning 
(Kolb \& Kolb, 2005). Hal ini karena pengalaman secara langsung akan memiliki dampak yang lebih kuat dibandingkan dengan pengalaman yang hanya dialami secara kognitif. Pada pelatihan yang dilakukan dengan siklus Kolb berguna untuk menentukan alur dan jalannnya kegiatan dalam pelatihan.

Pengalaman konkrit (concreate experience) pada pelatihan dilakukan dengan melakukan percobaan untuk membayangkan kejadian dalam bentuk permainan. Pengamatan reflektif (reflective observation) melakukan refleksi pada pengalaman pribadi. Konseptualisasi abstrak (abstrack conceptualization) menjelaskan terkait materi-materi pelatihan. Percobaan aktif (active experimentation) mencoba mengerjakan tantangan yang ada pada aplikasi PENGMAS.

Pelatihan disusun berdasarkan Taksonomi Bloom yang terdiri dalam tiga tahap yang diadaptasi oleh (Betts, 2020) dan (Christopher et al., 2004). Pada tingkat rendah yang ingin dicapai adalah pengetahuan dan pemahaman partisipan terhadap materi. Pada tingkat menengah yang ingin dicapai adalah pengaplikasian dan analisis yang dilakukan oleh partisipan pelatihan. Pada tingkat tinggi yang ingin dicapai dalam pelatihan adalah sintesis dan evaluasi dimana partisipan pelatihan melibatkan penerapan konsep baru yang dapat berkembang menjadi solusi di kehidupannya.

Rumusan masalah yang ingin dijawab yaitu: apakah ada peningkatan kebahagiaan psikologis kepada guru SD perempuan yang memiliki anak kelas 1-3 SD yang mendapatkan pelatihan dengan materi mindfulness dan komunikasi?
Hipotesis penelitian ini yaitu: ada peningkatan kebahagiaan psikologis kepada guru SD perempuan yang memiliki anak kelas 1-3 SD yang mendapatkan pelatihan materi mindfulness dan komunikasi. Tujuan penelitian meningkatkan kebahagiaan psikologis guru SD perempuan yang memiliki anak kelas 1-3 SD.

\section{METODE PENELITIAN}

Partisipan penelitian adalah guru SD perempuan di Indonesia yang memiliki anak kelas 1-3 SD yang melakukan PJJ. Lokasi pelatihan dilakukan melalui aplikasi zoom untuk penyampaian materi pelatihan. Selain itu, penelitian menggunakan media aplikasi android PENGMAS UI yang bisa diunduh di playstore untuk mengerjakan tantangantantangan dalam pelatihan. Aplikasi PENGMAS ini diharapkan memudahkan partisipan dalam memahami materi yang disampaikan selama pelatihan. Materi pelatihan terdiri dari mindfulness, komunikasi dan kebahagiaan psikologis.

Teknik pengumpulan data yang dilakukan dalam penelitian ini dilakukan dengan wawancara serta pengisian kuesioner. Kuesioner terdiri dari 3 alat yakni: FFMQ, PWBS, dan R-FCP. Ketiga alat ukur ini mengukur mindfulness, kebahagiaan psikologis serta pola komunikasi. Desain penelitian ini one group pretest-posttest design. Adapun data yang diperoleh dari pengukuran akan dianalisis menggunakan SPSS dengan menggunakan teknik analisis Wilcoxon signed-rank.

Pengukuran membandingkan nilai partisipan sebelum mengikuti pelatihan dan setelah mengikuti pelatihan. Variabel 
pada penelitian ini adalah pelatihan mindfulness dan komunikasi, serta kebahagiaan psikologis. Pada akhir penelitian, peneliti ingin menguji sejauh mana pemberian pelatihan mindfulness dan komunikasi memiliki dampak pada kebahagiaan psikologis pada guru perempuan pada jenjang SD yang memiliki anak kelas 1-3 SD.

\section{HASIL DAN PEMBAHASAN}

Proses penelitian ini meliputi beberapa tahapan, yaitu: tahap persiapan, tahap baseline, tahap persiapan intervensi, tahap intervensi dan tahap evaluasi. Adapun proses penelitian secara lebih jelas dapat dilihat dalam gambar 1. proses penelitian. Setiap tahapan dalam penelitian menghasilkan data-data terkait guru SD perempuan yang memiliki anak kelas 1-3 SD selama pandemi COVID-19.

Pada tahap persiapan pelatihan, peneliti melakukan proses need assessment dengan menggali fenomenafenomena terkait COVID-19 dan pendidikan di Indonesia. Peneliti mengikuti webinar-webinar dengan topik terkait. Hasilnya peneliti dan tim Pengmas UI memilih untuk melakukan intervensi terkait kebahagiaan psikologis pada guru SD perempuan.

Kaji etik diurus pada Komite Etik Fakultas Psikologi Universitas Indonesia. Kaji etik dinyatakan layak dan sesuai prosedur penelitian dibuktikan dengan terbitnya bukti surat keterangan lolos kaji etika penelitian Nomor: 875/ F.Psi.KomiteEtik/ PDP.04.00/2020.

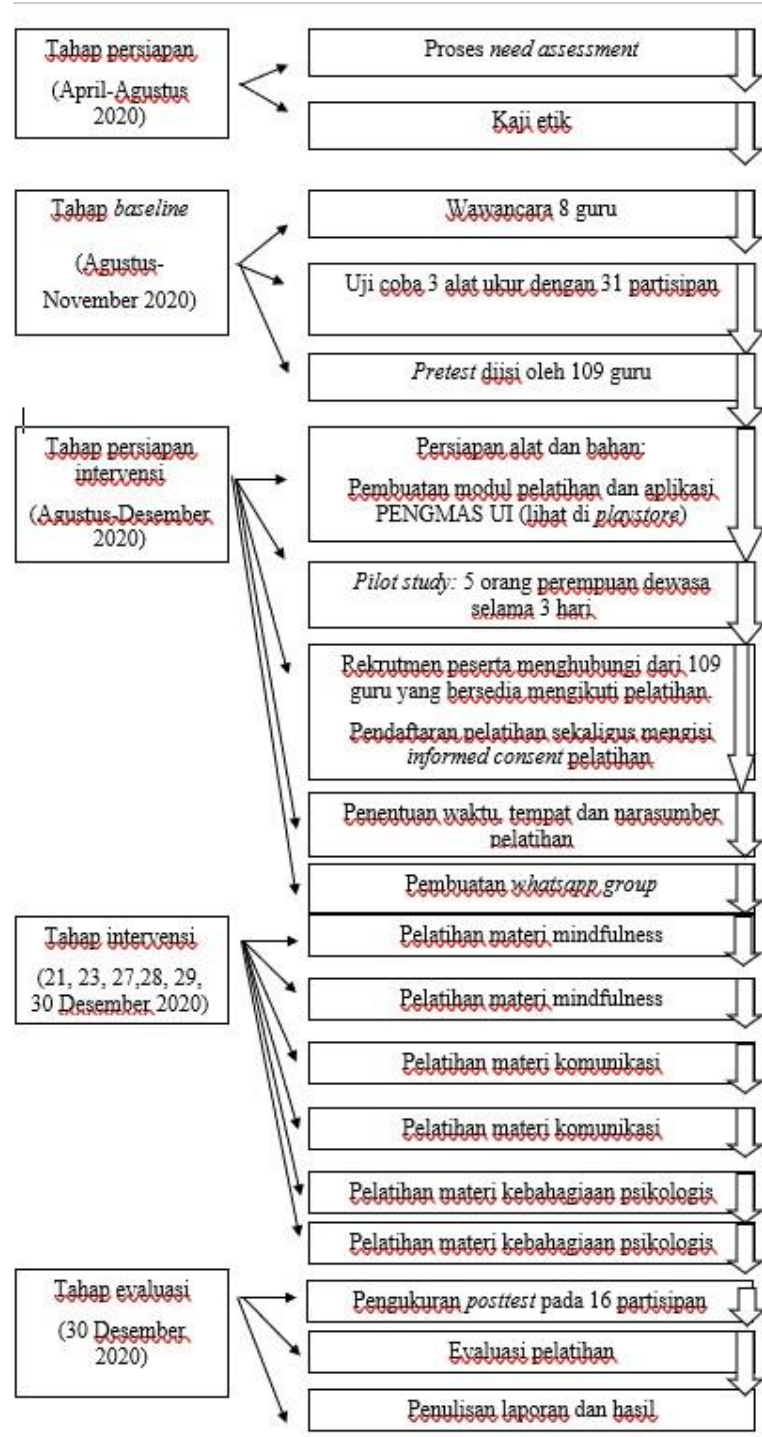

Gambar 1. Proses penelitian

Pada tahap baseline peneliti melakukan wawancara kepada 8 guru SD perempuan di beberapa kota/kabupaten di Indonesia (Kabupaten Nganjuk, Kabupaten Bekasi, Blitar dan Klaten). Adapun ringkasan dari hasil wawancara ditemukan 17 informasi terkait dampak PJJ pada guru SD perempuan yang memiliki anak kelas 1-3 SD.

Temuan hasil wawancara, yaitu:

a. Sebagian guru merasa kebingungan dan stres dalam menjalani dampak PJJ.

b. Guru-guru memiliki kendala membagi waktu untuk melaksanakan tugasnya sebagai orangtua yang mendampingi 
anaknya dan menjadi guru untuk murid-muridnya.

c. Perasaan-perasaan negatif sempat dirasakan oleh guru-guru seperti jenuh, bosan, khawatir, cemas, patah semangat dan takut saat PJJ.

d. Guru-guru memiliki strategi-strategi yang digunakan selama mendampingi anak dirumah saat PJJ.

e. Sebagian anak dilibatkan dalam pengambilan keputusan.

f. Guru merasakan repot dengan tugas yang dikerjakan baik sebagai orangtua maupun guru saat PJJ.

g. Anak lebih menurut dan menyukai interaksi dengan guru mereka dibandingkan dengan orangtua mereka dalam urusan belajar. Meskipun orangtua mereka berprofesi sebagai guru.

h. Pembelajaran secara langsung lebih disukai dibanding PJJ.

i. Interaksi orangtua dengan anak tidak selalu dalam kondisi yang baik dan harmonis.

j. Tidak semua orangtua memiliki kesepakatan-kesepakatan dengan anaknya.

k. Partisipan terkadang spontan marah saat situasi tidak menyenangkan seperti terlalu lelah.

l. Menjadi guru di kelas lebih mudah dibanding menjadi guru untuk anak sendiri.

$\mathrm{m}$. Jam kerja yang lebih panjang pada guru yang mengalami PJJ karena koreksi tugas siswa hingga malam.

n. Perilaku anak yang tidak mudah menurut dan terpengaruh kondisi perasaannya seperti perasaan ingin bermain, belum ingin belajar atau juga jenuh. o. Adanya kendala pada sinyal dan jaringan. Selain itu, meskipun mendapat bantuan kuota internet dari pemerintah, ada pengakuan dari salah satu guru bahwa siswanya ada yang tidak bisa memanfaatkan kuota tersebut karena HP mereka tidak cukup mendukung untuk menggunakan kuota tersebut (belum memiliki jaringan 4G).

p. Adanya kendala pada kemampuan fokus untuk menyelesaikan pekerjaan mereka dalam satu waktu yang bersamaan.

q. Menjaga komunikasi antara walimurid dan guru menjadi hal penting agar bisa menginformasikan urusan sekolah dengan lebih terbuka dan mendalam.

Selanjutnya, juga dilakukan uji coba dan uji keterbacaan alat ukur yang dilakukan kepada 31 partisipan dengan kriteria: perempuan dewasa yang bekerja dari rumah (WFH) yang memiliki anak kelas 1-3 SD yang melakukan PJJ. Uji alat ukur dilakukan tidak pada populasi guru karena kekhawatiran akan kurangnya partisipan pelatihan nantinya karena partisipan pelatihan sangat spesifik. Namun, sebagai pertanggung jawaban metodologis, karakteristik dalam uji coba alat ukur sendiri memiliki kemiripan yang tinggi dengan karakteristik penelitian, perbedaannya hanya pada profesinya.

Alat ukur yang diuji cobakan sebelumnya telah melalui proses adaptasi. Ketiga alat ukur ini adalah: Psychological Well-Being Scale (PWBS) yang dikembangkan oleh Ryff, (2013) yang sebelumnya juga telah diadaptasi dalam bahasa Indonesia oleh (Adiwena, 2019), Five Facet Mindfulness Scale-15 (FFMQ-15) alat ukur versi singkat dari $\mathrm{Gu}$ et al. (2016) dan Revised Family Communication 
Pattern (R-FCP) yang sebelumnya diadaptasi dalam Bahasa Indonesia oleh Asriati (2017). Hasil reliabilitas ketiga alat ukur tergolong baik dilihat dari nilai alpha Cronbach $>0,75$.

Berikut ini hasil reliabilitas ketiga alat ukur yang digunakan dalam penelitian:

Tabel 1: Hasil reliabilitas alat ukur

\begin{tabular}{|c|c|c|c|}
\hline No & $\begin{array}{l}\text { Skala } \\
\text { Pengukuran }\end{array}$ & $\begin{array}{l}\text { Jumlah } \\
\text { aitem }\end{array}$ & Reliabilitas \\
\hline 1. & $\begin{array}{l}\text { Psychological } \\
\text { Well-Being Scale } \\
(P W B S)\end{array}$ & 19 & 0,92 \\
\hline 2. & $\begin{array}{l}\text { Five Facet } \\
\text { Mindfulness } \\
\text { Scale-15 (FFMQ- } \\
\text { 15) }\end{array}$ & 15 & 0,82 \\
\hline \multirow[t]{2}{*}{3.} & $\begin{array}{l}\text { Revised Family } \\
\text { Communication } \\
\text { Pattern (R-FCP) } \\
\text { dimensi } \\
\text { conversation } \\
\text { orientation }\end{array}$ & 12 & 0,93 \\
\hline & $\begin{array}{l}\text { Revised Family } \\
\text { Communication } \\
\text { Pattern (R-FCP) } \\
\text { dimensi } \\
\text { conformity }\end{array}$ & 9 & 0,83 \\
\hline
\end{tabular}

Setelah alat ukur dinyatakan valid dan reliabel. Alat ukur digunakan untuk melakukan pengukuran pretest. Pretest berhasil diisi oleh 109 guru SD perempuan yang memiliki anak kelas 1-3 SD yang melakukan PJJ.. Selanjutnya, pada tahap persiapan intervensi, peneliti bersama Tim Pengmas UI menyusun modul pelatihan dengan tiga materi yang akan disampaikan dalam pelatihan yakni: mindfulness, komunikasi dan kebahagiaan psikologis. Serta membuat aplikasi PENGMAS.

Peneliti juga melakukan pilot study untuk memastikan bahwa materi yang akan disampaikan dalam pelatihan mudah untuk dipahami dan aplikasi PENGMAS dapat digunakan oleh partisipan. Pilot study dilakukan selama 3 hari dengan 5 partisipan ibu-ibu serta Tim Pengmas UI.

Rekrutmen partisipan penelitian dilakukan kepada 109 guru yang telah mengikuti pretest. Partisipan yang bersedia mengikuti pelatihan akan dihubungi kembali oleh peneliti dan diminta untuk mengisi informed consent. Hasil Rekapitulasi menunjukkan partisipan yang mendaftarkan diri sejumlah 21 partisipan sesuai dengan kriteria penelitian. Sedangkan target partisipan yang ingin didapat sebenarnya 30 partisipan dengan pertimbangan agar proses pelatihan bisa interaktif dan maksimal serta menyesuaikan dana pelatihan yang dimiliki.

Proses selanjutnya peneliti membuat grup whatsapp yang digunakan sebagai media untuk berkomunikasi kepada partisipan pelatihan. Berdasarkan 21 partisipan yang sesuai kriteria dan mendaftar dalam pelatihan hanya 16 orang yang datanya bisa diolah dalam analisis hasil. Hal ini disebabkan 1 orang partisipan hanya mengikuti 1 kali pelatihan, 1 orang partisipan hanya mengikuti 3 kali pelatihan dengan 2 topik materi, 3 orang partisipan lainnya tidak pernah hadir dalam pelatihan.

Pelatihan sendiri berlangsung selama 6 hari yaitu tanggal: 21, 23, 27, 28, 29, 30 Desember 2020. Pelatihan dilakukan pada malam hari pada pukul 19.00 WIB dengan durasi materi kurang lebih 60 menit, kecuali pada hari pertama dan terakhir pelatihan durasi diperpanjang karena adanya pembukaan dan penutupan pelatihan. Pemilihan waktu pada malam hari dan diwaktu guru dalam waktu libur sekolah dianggap 
meminimalisir atrisi partisipan secara signifikan. Selain itu didukung pengakuan partisipan yang menyebutkan bahwa pemilihan waktunya tepat dan sesuai.

Setiap partisipan yang mengikuti pelatihan berhak mendapatkan akses masuk pada aplikasi PENGMAS dan menerima uang pengganti pulsa sebesar Rp20.000,00 untuk setiap sesi yang diikuti dengan kata lain jika mengikuti pelatihan selama 6 sesi maka berhak menerima Rp120.000,00 serta di akhir pelatihan terdapat pemilihan 3 partisipan teraktif yang akan mendapatkan hadiah.

Gambaran umum partisipan yang mengikuti pelatihan dapat dilihat dari tabel 2. Pendidikan terakhir partisipan mayoritas lulus S1 dan mayoritas usia partisipan antara 36-40 tahun. Sedangkan domisili partisipan pelatihan berasal dari 9 kota/kabupaten di Indonesia.

Tabel 2: Gambaran umum partisipan

\begin{tabular}{lll}
\hline Klasifikasi & Keterangan & Jumlah \\
& & \\
\hline Usia & $31-35$ & 5 \\
& $36-40$ & 9 \\
Pendidikan & SMA & 2 \\
terakhir & D1/D2/D3 & 1 \\
& S1 & 1 \\
& S2 & 13 \\
Domisili & Ambon & 1 \\
& Bogor & 1 \\
& Depok & 2 \\
& Jakarta & 2 \\
& Kab. Nganjuk & 2 \\
& Tulang Bawang Barat & 4 \\
& Tasikmalaya & 1 \\
& Karangploso & 1 \\
& Tangerang & 1 \\
\hline
\end{tabular}

Hasil pengukuran pada 16 partisipan terdiri dari pengukuran mindfulness, komunikasi, dan kebahagiaan psikologis. Pada pengukuran mindfulness nilai partisipan dibandingkan dari nilai yang diperoleh saat pretest dan nilai posttest.
Berikut ini hasil yang diperoleh berdasarkan analisis Wilcoxon signed-rank test.

Tabel 3. Perbandingan nilai mindfulness

\begin{tabular}{lll}
\hline Keterangan & Jumlah & $\begin{array}{l}\text { Nilai } \\
\text { Rata- } \\
\text { rata }\end{array}$ \\
\hline Nilai negatif* & 3 & 9,00 \\
Nilai positif* & 12 & 7,75 \\
Nilai sama*** & 1 & \\
Z score & $-1,88$ & \\
$\mathrm{P}$ & 0,06 & \\
* posttest mindfulness < pretest mindfulness \\
** posttest mindfulness $>$ pretest mindfulness \\
*** posttest mindfulness = pretest mindfulness
\end{tabular}

Berdasarkan tabel diketahui bahwa nilai negatif terdapat 3 orang yang mengalami penurunan nilai pada posttest mereka. Pada nilai positif diketahui terdapat 12 orang yang mengalami peningkatan nilai, artinya nilai posttest mindfulness mereka lebih tinggi dibandingkan dengan nilai pretestnya. Sedangkan untuk nilai yang sama terdapat 1 orang yang nilai pretest dan nilai posttestnya tidak terjadi perubahan. Nilai signifikansi yang terdapat pada tabel menunjukkan pada angka $(p=0,06)$ berarti tidak ada perbedaan pengetahuan mindfulness pada guru.

Tingkat pengetahuan mindfulness guru dapat dilihat dari perolehan skor individu. Hasil perbandingan pretestposttest pada tabel 4 menunjukkan bahwa partisipan telah memiliki pengetahuan mindfulness yang cukup baik pada pretest, terlihat dari skor rata-rata yang termasuk pada kategori sedang pada pretest $(M=61,75)$ dan pengetahuan yang baik pada posttest dilihat dari skor yang tinggi pada rata-rata posttest $(M=65,75)$ dari skor maksimal 90 poin. 


\begin{tabular}{ccc}
$\begin{array}{l}\text { Tabel 4: } \\
\text { mindfulness }\end{array}$ & Perbandingan & pretest-posttest \\
\hline Partisipan & $\begin{array}{l}\text { Pretest } \\
\text { (M=61,75) }\end{array}$ & $\begin{array}{l}\text { Posttest } \\
(\mathrm{M}=65,75)\end{array}$ \\
\hline 1 & 50 & 64 \\
2 & 72 & 70 \\
3 & 58 & 60 \\
4 & 61 & 65 \\
5 & 55 & 58 \\
6 & 67 & 88 \\
7 & 62 & 66 \\
8 & 53 & 55 \\
9 & 60 & 70 \\
10 & 60 & 84 \\
11 & 55 & 56 \\
12 & 73 & 65 \\
13 & 66 & 69 \\
14 & 71 & 56 \\
15 & 65 & 65 \\
16 & 60 & 61 \\
\hline
\end{tabular}

Pengukuran komunikasi yang didapatkan dari 16 partisipan pelatihan dapat diketahui pada tabel 5 .

Tabel 5: Perbandingan nilai komunikasi

\begin{tabular}{lll}
\hline Keterangan & Jumlah & $\begin{array}{l}\text { Nilai } \\
\text { Rata- } \\
\text { rata }\end{array}$ \\
\hline Nilai negatif* & 6 & 7,83 \\
Nilai positif** & 9 & 8,11 \\
Nilai sama*** & 1 & \\
Z score & $-0,74$ & \\
$\mathrm{P}$ & 0,46 & \\
\hline * posttest komunikasi < pretest komunikasi \\
** posttest komunikasi> pretest komunikasi \\
*** posttest komunikasi= pretest komunikasi
\end{tabular}

Berdasarkan tabel diketahui nilai negatif terdapat 6 orang mengalami penurunan nilai pada posttest mereka. Pada nilai positif diketahui bahwa terdapat 9 orang yang mengalami peningkatan nilai, artinya nilai posttest komunikasi mereka lebih tinggi dibandingkan dengan nilai pretestnya. Sedangkan untuk nilai yang sama terdapat 1 orang yang artinya nilai pretest dan nilai posttestnya tidak terjadi perubahan. Nilai signifikansi yang terdapat pada tabel menunjukkan pada angka ( $p=$ $0,46)$, hal ini berarti tidak ada perbedaan pengetahuan komunikasi pada guru sebelum dan setelah intervensi dilakukan.

Tingkat pengetahuan komunikasi guru dapat dilihat dari perolehan skor individu. Hasil masing-masing partisipan dapat dilihat dari tabel sebagai berikut:

Tabel 6. Perbandingan pretest-posttest komunikasi

\begin{tabular}{ccc}
\hline Partisipan & $\begin{array}{l}\text { Pretest } \\
(\mathrm{M}=90,88)\end{array}$ & $\begin{array}{l}\text { Posttest } \\
(\mathrm{M}=94,00)\end{array}$ \\
\hline 1 & 62 & 80 \\
2 & 93 & 101 \\
3 & 88 & 88 \\
4 & 108 & 87 \\
5 & 90 & 94 \\
6 & 92 & 84 \\
7 & 90 & 101 \\
8 & 64 & 105 \\
9 & 121 & 122 \\
10 & 92 & 83 \\
11 & 78 & 85 \\
12 & 92 & 86 \\
13 & 98 & 110 \\
14 & 89 & 90 \\
15 & 97 & 93 \\
16 & 100 & 95 \\
\hline
\end{tabular}

Hasil skor tersebut menunjukkan bahwa partisipan telah memiliki pengetahuan komunikasi yang baik pada pretest, terlihat dari skor rata-rata yang termasuk pada kategori tinggi pada pretest $(M=90,88)$ dan pengetahuan yang baik pada posttest dilihat dari skor yang tinggi pada rata-rata posttest $(\mathrm{M}=94,00)$ dari skor maksimal 126 poin.

Pengukuran kebahagiaan psikologis yang didapatkan dari 16 partisipan pelatihan dapat diketahui pada tabel 7 dibawah ini. 
Tabel 7. Perbandingan nilai kebahagiaan psikologis

\begin{tabular}{lll}
\hline Keterangan & Jumlah & $\begin{array}{l}\text { Nilai } \\
\text { Rata- } \\
\text { rata }\end{array}$ \\
\hline Nilai negatif* & 5 & 8,80 \\
Nilai positif** & 9 & 6,78 \\
Nilai sama*** & 2 & \\
Z score & $-0,53$ & \\
$\mathrm{P}$ & 0,59 & \\
* posttest kebahagiaan psikologis \\
$<$ pretest kebahagiaan psikologis \\
** posttest kebahagiaan psikologis \\
$>$ pretest kebahagiaan psikologis \\
*** posttest kebahagiaan psikologis \\
$=$ pretest kebahagiaan psikologis
\end{tabular}

Berdasarkan tabel diketahui nilai negatif terdapat 5 orang artinya ada penurunan nilai pada posttest. Pada nilai positif diketahui terdapat 9 orang yang mengalami peningkatan nilai artinya nilai posttest kebahagiaan psikologis mereka lebih tinggi dibandingkan dengan nilai pretestnya. Sedangkan nilai yang sama terdapat 2 orang artinya nilai pretest dan nilai posttestnya tidak terjadi perubahan. Nilai signifikansi yang terdapat pada tabel menunjukkan pada angka $(p=0,59)$, hal ini berarti bahwa tidak ada perbedaan pengetahuan kebahagiaan psikologis pada guru sebelum dan setelah intervensi.

Tingkat pengetahuan kebahagiaan psikologis guru dapat dilihat dari perolehan skor individu. Hasil masingmasing partisipan dapat dilihat dari tabel sebagai berikut:
Tabel 8. Perbandingan pretest-posttest kebahagiaan psikologis

\begin{tabular}{ccc}
\hline Partisipan & $\begin{array}{l}\text { Pretest } \\
(\mathrm{M}=90,00)\end{array}$ & $\begin{array}{c}\text { Posttest } \\
(\mathrm{M}=90,94)\end{array}$ \\
\hline 1 & 78 & 68 \\
2 & 103 & 108 \\
3 & 85 & 85 \\
4 & 111 & 102 \\
5 & 88 & 76 \\
6 & 87 & 89 \\
7 & 97 & 101 \\
8 & 64 & 71 \\
9 & 104 & 103 \\
10 & 87 & 111 \\
11 & 88 & 91 \\
12 & 102 & 104 \\
13 & 96 & 96 \\
14 & 90 & 71 \\
15 & 75 & 90 \\
16 & 85 & 89 \\
\hline
\end{tabular}

Hasil skor tersebut menunjukkan bahwa partisipan telah memiliki pengetahuan kebahagiaan psikologis yang baik pada pretest, terlihat dari skor rata-rata yang termasuk pada kategori tinggi pada pretest $(M=90,00)$ dan pengetahuan yang baik pada posttest dilihat dari skor yang tinggi pada rata-rata posttest $(\mathrm{M}=90,94)$ dari skor maksimal 114 poin.

Hasil penelitian yang menunjukkan tidak adanya perubahan yang signifikan dalam penelitian ini menurut analisis peneliti disebabkan oleh beberapa hal yaitu:

a. Nilai pretest partisipan yang mengikuti pelatihan telah berada pada nilai dalam kategori sedang dan tinggi. Tidak terdapat partisipan yang memiliki nilai rendah pada pretest mereka.

b. Durasi waktu intervensi dan jumlah sesi yang relatif singkat yakni 6 sesi pertemuan dengan masing-masing berdurasi kurang lebih 1 jam pada sesi kedua hingga keempat dan 2 jam pada sesi pertama dan terakhir. Waktu yang relatif singkat ini membuat kesulitan untuk membuktikan efektivitas 
intervensi. Pada penelitian sebelumnya durasi pelatihan yang memberikan pengaruh dilaksanakan lebih dari 4 minggu (Fledderus et al., 2010).

c. Pilot study pada penelitian dilakukan dalam durasi yang dipersingkat, hal ini bisa membuat kurang optimalnya proses evaluasi pada persiapan intervensi yang dilakukan.

d. Pelatihan dilakukan secara daring. Selain kelebihan yang dimiliki, pelatihan secara daring juga memiliki kelemahan-kelemahan lebih banyak dibandingkan dengan pelatihan secara langsung. Hal ini dikarenakan, pada pelatihan secara daring interaksi partisipan dan fasilitator tidak bisa diobservasi secara langsung. Selain itu, fasilitator tidak bisa mengontrol secara penuh hal-hal yang bisa mendistraksi jalannnya pelatihan seperti kondisi masing-masing partisipan pelatihan.

Meskipun hasil penelitian ini tidak menunjukkan hasil yang sejalan dengan penelitian sebelumnya bahwa mindfulness disebut sebagai faktor yang berpengaruh pada peningkatan kebahagiaan psikologis (Sanoveriana \& Fourianalistyawati, 2017)). Hal ini tidak lantas sepenuhnya mencerminkan kegagalan intervensi yang dilakukan. Meskipun tidak naik secara signifikan, mereka juga belajar komunikasi dengan lebih baik dalam keluarganya.

Seperti yang dikatakan dalam penelitian sebelumnya bahwa pola komunikasi keluarga akan membentuk karakter seseorang dalam bersikap terhadap satu anggota keluarga dengan anggota yang lainnya. Pola komunikasi keluarga ini yang nantinya juga berpengaruh terhadap karakteristik sebuah keluarga (Koerner \& Fitzpatrick,
2002). Keluarga yang terbuka akan saling belajar memahami dan hal ini terkait dengan kebahagiaan psikologis.

Hasil evaluasi yang dilakukan peneliti pada akhir pelatihan menunjukkan adanya kepuasan partisipan dalam mengikuti pelatihan dan merasakan manfaat dari pelatihan yang dilakukan. Evaluasi dalam pelatihan dilakukan untuk mengetahui sejauh mana harapan dan kepuasan partisipan dalam mengikuti pelatihan.

Pernyataan evaluasi harapan diisi berdasarkan skala 1-6 yang menunjukkan skala 1 sangat tidak sesuai hingga skala 6 sangat sesuai. Pernyataan evaluasi kepuasan sama dengan pernyataan harapan tetapi berbeda pada keterangan skalanya. Skala 1 menunjukkan sangat tidak puas hingga skala 6 sangat puas. Pada pernyataan "Pelatihan mampu meningkatkan kebahagiaan psikologis" evaluasi kesesuaian pelatihan berada pada penilaian cukup sesuai hingga sangat sesuai. Cukup sesuai diisi oleh 2 partisipan, 7 partisipan memilih sesuai dan 7 lainnya memilih sangat sesuai.

Sedangkan pada evaluasi kepuasan partisipan, 3 partisipan merasa cukup puas, 7 partisipan puas dan 6 lainnya merasa sangat puas. Pada pernyataan "Program pelatihan sesuai kebutuhan" evaluasi kesesuaian berada pada kategori cukup sesuai hingga sangat sesuai. Sejumlah 2 partispan memilih cukup sesuai, 9 partisipan memilih sesuai dan 5 lainnya memilih sangat sesuai. Sedangkan pada evaluasi kepuasan partisipan, terdapat 3 partisipan merasa cukup puas, 7 partisipan puas dan 6 lainnya merasa sangat puas. 


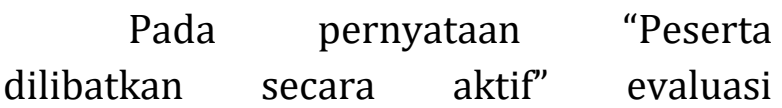
kesesuaian berada pada kategori cukup sesuai hingga sangat sesuai. Kategori cukup sesuai dipilih oleh 1 partisipan, 7 partisipan memilih sesuai dan 8 lainnya memilih sangat sesuai. Sedangkan pada evaluasi kepuasan partisipan, terdapat 3 partisipan merasa cukup puas, 4 partisipan puas dan 9 lainnya merasa sangat puas.

Selain mengisi pernyataan evaluasi harapan dan kepuasan, partisipan juga diminta untuk mengisi penilaian terhadap pelatihan yang dilakukan. Sebagian besar partisipan menilai bahwa pelatihan memiliki manfaat yang positif bagi mereka. Berikut ini adalah beberapa penilaian dari pelatihan:

"Pelatihan seperti ini lah yang diperlukan oleh para guru sekaligus orang tua, semoga bisa berlanjut. ada rasa haru dan sedih ketika pelatihan ini selesai, pasti akan kangen dengan suasana pelatihan walau kami tdk saling mengenal satu sama lain pada awalnya. Terima kasih"

"Terimakasih atas ilmu yg di berikan ke pada kami semoga dapat bermanfaat untuk kami di rumah ataupum di sekolah."

"Semoga kegiatan2 webinar yg membangun motivasi positif bisa sering diadakan."

"Waktu pelaksanaan pelatihan sangat pas dan sesuai. Host dan pematerinya mantab dan materinya sangat bermanfaat bagi kami terima kasih. Lanjutkan."

"Dibuat kelanjutan pelatihannya atau ada wadah untuk pemantauan dari pihak UI kepada kami para guru terkait materi yang disampaikan. Karena materi yg disampaikan ini sangat bermanfaat dan relevan dlm masa pandemi ini." "Saran saya: agar kegiatan seperti ini sering dilaksanakan. Bukan hanya ketika Covid. Saya sangat berterima kasih kepada team UI untuk segala ilmu yang di bagikan. Sangat bermanfaat untuk kehidupan saya."

"Program sangat menarik. Mengena pada diri kita. Semoga ada pelatihan lagi."

Penilaian yang baik dari partisipan terkait manfaat pelatihan ini bisa menunjukkan bahwa pelatihan yang dilakukan memiliki potensi untuk dikembangkan dengan lebih baik lagi.

\section{SIMPULAN}

"Pelatihan Peningkatan Kebahagiaan Psikologis pada Guru di Masa Pandemi COVID-19" yang bertujuan untuk meningkatkan kebahagiaan psikologis dengan meningkatkan keterampilan mindfulness dan komunikasi dari hasil pengukuran statistik diketahui bahwa tidak terjadi peningkatan yang signifikan pada pengetahuan partisipan terhadap kebahagiaan psikologis. Sedangkan hasil kualitatif yang diperoleh menunjukkan bahwa intervensi memiliki potensi positif untuk meningkatkan kebahagiaan psikologis dan memiliki manfaat yang baik bagi partisipan pelatihan.

\section{UCAPAN TERIMAKASIH}

Terima kasih peneliti ucapkan kepada Tim Pengabdian Masyarakat UI: Dr. Dipl. Psych. Ratna Djuwita, Prof. Dr. Frieda M. Mangunsong S., M.Ed., Psikolog., 
Shofa Dzakiah, S.Psi., Noori Lukman Pradibto, S.Psi., berkat kerja keras dan kerja sama yang baik, proses pelatihan dapat berjalan dan terselesaikan dengan baik. Terima kasih peneliti sampaikan juga kepada Direktorat Pemberdayaan dan Pengabdian Masyarakat UI yang telah memberikan dana hibah dalam penelitian Tim Pengmas UI. Serta seluruh pihak terkait yang turut membantu terlaksananya pelatihan ini.

\section{DAFTAR PUSTAKA}

Adiwena, B. (2019). Alam membawa kebahagiaan: peranan kedekatan dengan alam, persepsi kerusakan lingkungan, dan kontak dengan alam terhadap kebahagiaan hidup masyarakat urban di Indonesia. In Universitas Indonesia.

Asriati, R. (2017). Asosiasi Pola Komunikasi Keluarga Dan Conduct Problems Pada Siswa Sma Di Dki Jakarta. o806455143, 1-10.

Betts, S. (2020). Teaching and Assessing Basic Concepts To Advanced Applications : Teaching and Assessing Basic Concepts To Advanced Applications: Using Bloom' S Taxonomy To. May.

Borness, C., Proudfoot, J., Crawford, J., \& Valenzuela, M. (2013). Putting Brain Training to the Test in the Workplace: A Randomized, Blinded, Multisite, ActiveControlled Trial. PLoS ONE, 8(3), 1-8. https://doi.org/10.1371/journal.pone.005998 2

Braun, S. S., Roeser, R. W., Mashburn, A. J., \& Skinner, E. (2019). Middle School Teachers' Mindfulness, Occupational Health and Well-Being, and the Quality of TeacherStudent Interactions. Mindfulness, 10(2), 245-255. https://doi.org/10.1007/s12671-0180968-2

Christopher, M. M., Thomas, J. A., \& TallentRunnels, M. K. (2004). Raising the bar: Encouraging high level thinking in online discussion forums. Roeper Review, 26(3), 166-171.

https://doi.org/10.108o/02783190409554262

Dewi, W. A. F. (2020). Dampak COVID-19 terhadap Implementasi Pembelajaran Daring di Sekolah Dasar. Edukatif : Jurnal
Ilmu Pendidikan, 2(1), 55-61. https://doi.org/10.31004/edukatif.v2i1.89

Fledderus, M., Bohlmeijer, E. T., Smit, F., \& Westerhof, G. J. (2010). Mental health promotion as a new goal in public mental health care: A randomized controlled trial of an intervention enhancing psychological flexibility. American Journal of Public Health, $\quad$ 100(12), 2372-2378. https://doi.org/10.2105/AJPH.2010.196196

Gu, J., Strauss, C., Crane, C., Barnhofer, T., Karl, A., Cavanagh, K., \& Kuyken, W. (2016). Supplemental Material for Examining the Factor Structure of the 39-Item and 15-Item Versions of the Five Facet Mindfulness Questionnaire Before and After Mindfulness-Based Cognitive Therapy for People With Recurrent Depression. Psychological Assessment, 28(7), 791-802. https://doi.org/10.1037/pasoooo263.supp

Hunter, E. M., Clark, M. A., \& Carlson, D. S. (2019). Violating Work-Family Boundaries: Reactions to Interruptions at Work and Home. Journal of Management, 45(3), 12841308.

https://doi.org/10.1177/0149206317702221

Huppert, F. A. (2009). Psychological Well-being: Evidence Regarding its Causes and Consequences. Applied Psychology: Health and Well-Being, 1(2), 137-164. https://doi.org/10.1111/j.1758-

0854.2009.01008.x

Josefsson, T., Lindwall, M., \& Broberg, A. G. (2014). The Effects of a Short-term Mindfulness Based Intervention on Selfreported Mindfulness, Decentering, Executive Attention, Psychological Health, and Coping Style: Examining Unique Mindfulness Effects and Mediators. Mindfulness, $\quad 5(1), \quad 18-35$. https://doi.org/10.1007/s12671-012-0142-1

Koerner, F. A., \& Fitzpatrick, M. A. (2002). Understanding Family Communication Patterns and Family Functioning: The Roles of Conversation Orientation and Conformity Orientation. Annals of the International Communication Association, 26(1), 36-65. https://doi.org/10.108o/23808985.2002.1167 9010

Kolb, A. Y., \& Kolb, D. A. (2005). Learning styles and learning spaces: Enhancing experiential learning in higher education. Academy of Management Learning and Education, 4(2), 193-212. 
https://doi.org/10.5465/AMLE.2005.1726856 6

Nurmayanti, S., Thoyib, A., -, N., \& Irawanto, D. (2014). Work Family Conflict: A Review of Female Teachers in Indonesia. International Journal of Psychological Studies, $\quad 6(4)$, 134-142. https://doi.org/10.5539/ijps.v6n4p134

Purwanto, A., Pramono, R., Asbari, M., Santoso, P. B., Wijayanti, L. M., Choi, C. H., \& Putri, R. S. (2020). Studi Eksploratif Dampak Pandemi COVID-19 Terhadap Proses Pembelajaran Online di Sekolah Dasar. EduPsyCouns: Journal of Education, Psychology and Counseling, 2(1), 1-12. https://ummaspul.ejournal.id/Edupsycouns/article/view/397

Ryff, C. D. (2013). Psychological well-being revisited: Advances in the science and practice of eudaimonia. Psychotherapy and Psychosomatics, $\quad 83(1), \quad 10-28$. https://doi.org/10.1159/oo0353263

Sanoveriana, S., \& Fourianalistyawati, E. (2017). Work-Family Balance, Trait Mindfulness and Psychological Well-Being in MiddleAged Working Parents. UI Proceedings on Social Science and Humanities, 1.

Weiss, L. A., Westerhof, G. J., \& Bohlmeijer, E. T. (2016). Can we increase psychological wellbeing? The effects of interventions on psychological well-being: A meta-analysis of randomized controlled trials. PLoS ONE, 11(6), $\quad 1-16$. https://doi.org/10.1371/journal.pone.015809 2

Sumber wawancara pribadi:

Anita. (17 Oktober 2020). Wawancara Pribadi. Bahaun. (28 Oktober 2020). Wawancara Pribadi. Endri. (18 Oktober 2020). Wawancara Pribadi. Iin. (26 Oktober 2020). Wawancara Pribadi. Miftachur. (24 November 2020). Wawancara Pribadi.

Rita. (24 Oktober 2020). Wawancara Pribadi.

Sri Rahmi. (25 November 2020). Wawancara Pribadi.

Yuliani. (27 November 2020). Wawancara Pribadi. 